\title{
Fontes históricas e oralidade
}

Resumo: o presente texto sistematiza as relações entre o historiador e suas fontes, procurando elucidar questões teóricas e metodológicas emergentes da narrativa histórica. Duas questões conceituais vertebram o texto. Uma refere-se a construção de narrativas a partir de uma fonte escrita tradicional, indicando as limitações das possibilidades de conhecimento de culturas que não utilizam a linguagem escrita. Uma segunda questão emerge da multiplicidade de tempos do historiador, a partir de sua interação com as fontes, a linearidade da narrativa escrita também limita as possibilidades de conhecimento de grupos dominados. O texto finaliza apontando para uma questão central no debate de história oral, isto é, o historiador como produtor de documentação histórica.

Palavras-chave: História Oral, Fontes Históricas, Documentação Histórica.

Anos de experiência como professor e orientador de inúmeras teses de mestrado e doutorado, apontaram para a necessidade de sistematizar um texto didático enfocando as relações entre o historiador e sua documentação, incorporando a utilização de múltiplas alternativas, desde a documentação mais tradicional, até novas possibilidades abertas pelo desenvolvimento da tecnologia privilegiando as fontes orais, dada sua utilização intensiva e extensiva na área de Educação.

Esta constatação ganha maior significado, posto que a primeira geração de professores do ensino fundamental, que trabalhou com o ensino público de massas no Brasil, tem produzido depoimentos e memórias de riqueza e conteúdo admiráveis.

Este texto é totalmente construído apoiado em cursos ministrados, monografias e teses orientadas e artigos escritos em diferentes momentos, preponderantemente voltados para a elucidação de questões teóricas e metodológicas emergentes nesse processo vivido e compartilhado com alunos e orientandos.

* Doutor em História Econômica. Professora da Universidade Metodista de Piracicaba.

Movimento, Porto Alegre, v. 10, n. 3, p.133-154, setembro/dezembro de 2004 
Duas questões conceituais, apoiadas em documentação empírica, pistas e procedimentos vivenciados, balizam esta exposição. Uma primeira refere-se a construção de narrativas a partir da existência de uma fonte escrita tradicional, indicando as limitações das possibilidades de conhecimento de culturas que não utilizam a linguagem escrita, a partir de narrativas construídas pelos colonizadores europeus. Uma segunda questão refere-se a multiplicidade dos tempos do historiador, a partir de sua interação com as fontes, a linearidade da narrativa escrita, novamente limita as possibilidades de busca de pistas oriundas de grupos dominados.

De inicio trabalharemos com as narrativas construídas tendo por suporte uma fonte primária, a carta de Pero Vaz de Caminha, ${ }^{1}$ o escrivão da armada de Pedro Álvares Cabral. Como se sabe, este documento relata, através da óptica do colonizador, o primeiro contato entre o europeu e o nativo brasileiro. Neste caso, dois autores que se utilizaram dessas fontes merecerão especial atenção, Inezil Penna Marinho ${ }^{2}$ e Jair Jordão Ramos. ${ }^{3}$ Ambos constroem sua argumentação acerca das origens da História do Esporte, ou dos Desportos, no Brasil fundamentados neste documento, tendo-o como ponto de partida de seus textos. Este exemplo nos permitirá visualizar alguns equívocos no trato documental, demonstrando exemplarmente as limitações e os problemas mais elementares que os estudantes enfrentam em suas primeiras incursões no campo da pesquisa histórica.

Posterior à discussão da forma e das implicações na utilização desta fonte, argumentando sobre a impossibilidade da constituiçãoo do objeto de análise (esporte), pretendido pelos autores,

1 Existem várias edições publicadas deste documento, Penna Marinho apoiou-se na edição de 1939, lançada no Rio de Janeiro por S.D. e impressa por J. Borsoi Junior. Esta edição contém inúmeros erros, para confronto, utilizei, neste artigo a Carta a El Rei D.Manuel, em português moderno, com divisão em tópicos, glossário e índice remissivo, preparada por Leonardo Arroyo. São Paulo, Editora Dominus, 1963

2 Vários textos do autor foram consultados, ver especialmente: História da educação física e desportos no Brasil. Rio de janeiro. DEF-MES, 1952-53,4v. História da Educação Física no Brasil: exposição-bibliografia-legislação, São Paulo. Cia Brasil Editora.s.d. .Contribuição para a História da Educação Física e Desportos no Brasil: Brasil Colônia - Brasil Império - Brasil República. Rio de Janeiro. Imprensa Nacional, 1943.

3 Em especial Os exercícios físicos na história e na arte: do homem primitivo aos nossos dias. São Paulo Ibrasa. 1982. Ver ainda 'Educação Física e Desportos no Brasil: Considerações Gerais' in Revista Brasileira de Educação Física. (R.B.E.F.) MEC, $n^{\circ} 20$.

Movimento, Porto Alegre, v. 10, n. 3, p.133-154, setembro/dezembro de 2004 
apresentaremos um documento, produzido cerca de 340 anos depois da Carta de Caminha; trata-se de um relato de um viajante estrangeiro, Kidder, ${ }^{4}$ este documento é um precioso estudo dos costumes, paisagens e tipos encontrados por ele. A discussão objetiva estabelecer a relação entre diferentes tempos históricos na constituição de um objeto de estudo, quando formulado por narradores não pertencentes ao grupo, e/ou a situação histórica e cultural envolvida. Tanto Caminha, escrivão português, tendo como interlocutor o Rei de Portugal, para quem sua carta foi redigida, quanto Kidder, um missionário norte americano, elaborando um texto para o grande público, formulam conceitos e denominam coisas e situações, a partir do universo constituído por suas próprias referências culturais, neste caso exteriores a narrativa que ambos construíram, embora presentes nas exposições, tendo em vista os interlocutores à quem estes escritos foram dirigidos.

$\mathrm{Na}$ discussão que estamos propondo, existe uma evidente preocupação com dois aspectos fundamentais da atividade do historiador, de um lado temos a relação com as fontes primárias, e como decorrência desta discussão relativa a construção da narrativa histórica, estabelece-se uma outra relação com as fontes secundárias, produzidas a partir das fontes enunciadas nas exposições construídas a partir da documentação originária, ou construídas apesar das fontes apresentadas como referência. Estamos falando do processo de construção e reconstrução das fontes, o que assumimos ser tarefa específica do historiador.

Também, e em decorrência das concepções relativas ao uso das fontes primárias, ao colocar na construção de um tema o confronto de múltiplos tempos, procuramos afirmar que a construção do tempo histórico deve levar em conta seu ordenamento espacial, e a configuração cultural dos agentes produtores da documentação. Feitas estas ressalvas, que permitem compreender este texto com

4 Daniel Parish Kidder nasceu em 18 de outubro de 1815, em Darien no estado de Nova York. Por conta de suas atividades religiosas, posto que era um pasto metodista, veio ao Brasil difundir a Bíblia, patrocinado pela Sociedade Bíblica Americana. Em 1840, com o falecimento de sua mulher, Kidder retornou aos Estados Unidos, escrevendo suas Reminiscências de Viagens e Permanências no Brasil. São Paulo. Martins, Ed. Da Universidade de São Paulo, 1972, 2 vol.

5 Para uma reflexão instigante e erudita sobre o historiador e as fontes, ver H.I. Marrou Do Conhecimento Histórico. Trad. Ruy Belo, Lisboa. Editorial Asper,s.d. Muitas das críticas que serão formuladas neste texto, inspiraram-se, sem que isso constitua transferência de responsabilidade, no trabalho de Marrou, tanto quanto em Jacques Le Goff História e Memória. Trad. Bernardo Leitão.(et al.), $2^{\mathrm{a}}$ ed. Campinas, Editora da Unicamp, 1992.

Movimento, Porto Alegre, v. 10, n. 3, p.133-154, setembro/dezembro de 2004 
uma certa dimensão pedagógica, vamos aos indícios, freqüentemente apresentados como 'fatos'.

Inezil Penna Marinho inicia inúmeros de seus trabalhos com a mesma matriz utilizada em seu livro de maior calibre (1952/53), nestes textos, identifica as origens da História da educação física e dos esportes tratando do indígena brasileiro e dos primeiros colonizadores, ao relatar suas atividades físicas, tais como: canoagem, arco e flecha, lutas, dentre outras, ele nos remete ao tempo dos descobrimentos, formulando suas primeiras conclusões:

\begin{abstract}
No primeiro contato entre portugueses e índios do Brasil, tal qual o descreveu a célebre carta de Pero Vaz de Caminha, encontramos, como forma de captar a simpatia dos nativos, uma demonstração de ginástica acrobática, realizada pelo almoxarife Diogo Dias e assim descrita pelo escrivão da armada de Cabral: 'Depois de dançarem fez-lhes ali, andando no chão, muitas voltas ligeiras e salto real, de que eles se espantavam e riam e falavam muito'. Esta foi, sem dúvida, a primeira aula de ginástica realizada no Brasil.
\end{abstract}

Este é o argumento inicial de Penna Marinho, a História dos Esportes se constituem no Brasil já no desembarque de um dos membros da esquadra de Cabral. É bem verdade que o autor, utilizando outros documentos, tais como escritos dos jesuítas e de viajantes estrangeiros, todos convenientemente referenciados, reafirma sempre a habilidade dos índios no uso do arco e da flecha, sem mencionar explicitamente as palavras esporte, desporto ou educação física.

O argumento se desenvolve, dando noticias sobre, natação, canoagem, corridas, touradas e equitação. Nestas duas últimas atividades temos já a presença de portugueses e brasileiros; e como veremos adiante, a descrição das cavalhadas permite inferir que Penna Marinho estava, implicitamente se referindo às atividades dos índios, tendo em vista a prática de atividades de natureza esportiva.

Este mesmo trecho da Carta de Caminha é também ponto de partida dos trabalhos de Jair Jordão Ramos que, justiça seja feita, referencia com prioridade e destaque o pioneirismo e a 'argúcia' de Penna Marinho no levantamento e utilização das fontes primárias relativas ao tema. De fato Jordão Ramos radicaliza um pouco mais a análise do tema, periodizando "A história da educação física e dos desportos no Brasil" (R.B.E.F., p.13) em três diferentes fazes: Colônia, Império e República; a partir desta periodização, o autor afirmará (p.15) sobre a mesma parte já citada do mesmo documento utilizado por Caminha:

Movimento, Porto Alegre, v. 10, n. 3, p.133-154, setembro/dezembro de 2004 
...Foi a primeira "aula" de recreação e ginástica praticada em nossa terra. Igualmente, interpretando o fato com um pouco de fantasia, pode-se atribuir a Caminha a glória de ter sido o primeiro cronista desportivo do Brasil.

É possível identificar uma sutil diferença nos textos dos dois autores. Enquanto Jordão Ramos de maneira mais enfática, fala em História do desporto no período colonial, bem como na existência de um cronista desportivo; observe que a "fantasia" na interpretação se refere a Caminha, e não ao fato da existência de uma atividade desportiva, Inezil Penna Marinho, mais cuidadoso, ainda que referindose diretamente a possíveis modalidades esportivas, (arco e flecha, natação, canoagem, corridas a pé, marchas, touradas e equitação), apenas se refere a "atividades físicas", o que sugeriria um maior rigor teórico na abordagem do tema. Sugeriria, não fosse um pequeno deslize cometido ao referir-se mais detidamente a equitação.

Ao referir-se a equitação, mais precisamente as cavalhadas levadas a efeito no nordeste, quando da dominação holandesa, Penna Marinho relata a comemoração de uma trégua entre holandeses e espanhóis, naquele momento dominando o Brasil. Os batavos competiram em torneios eqüestres contra brasileiros e portugueses, neste relato o autor é traído quando, baseado em Frei Calado, ${ }^{6}$ afirma (p.17): “...Os prêmios parecem ter sido os mais valiosos até hoje disputados em competições desportivas no Brasil...". Como se pode ver, estamos diante de autores que concordam no essencial. A História do Esporte no Brasil pode ser narrada desde o momento em que o país foi descoberto, e seus primitivos moradores contatados.

Apresentado este primeiro bloco de documentos, objetivando compreender a História da introdução, ou se dermos crédito à análise dos narradores citados, a História da existência autóctone do esporte no Brasil, algumas questões se colocam:

1) Quais as perguntas que Penna Marinho e Jordão Ramos fizeram aos documentos, neste caso vamos nos restringir a Carta de Caminha, para obter estas respostas conclusivas, implícitas ou explícitas referentes a História do Esporte no Brasil?

2) A leitura do documento por parte dos autores, autoriza as conclusões afirmadas?

3) Que problemas teóricos e metodológicos podemos apontar a partir destas construções factuais narradas pelos autores?

6 Calado, F. M.- O valoroso lucidemo e Triunfo da Liberdade. Recife, 1942, 2 vol.

Movimento, Porto Alegre, v. 10, n. 3, p.133-154, setembro/dezembro de 2004 
Vamos a Carta de Caminha, justamente para avançar na contraposição de argumentos, ampliando o texto citado e trabalhado por Penna Marinho, no sentido de coloca-lo na sua mais ampla contextualização:

...E além do rio andavam muitos dêles dançando e folgando, uns diante os outros, sem se tomarem pelas mãos. E faziam-no bem. Passou-se então para a outra banda do rio Diogo Dias, que fôra almoxarife de Sacavém, o qual é homem gracioso e de prazer. Elevou consigo um gaiteiro nosso com sua gaita. Emeteu-se a dançar com êles, tomando-os pelas mãos; e êles folgavam eriam e andavam com êle muito bem ao som da gaita. Depois de dançarem fêz-Ihes ali muitas voltas ligeiras, andando no chão, e salto real, de que se êles espantavam e riam e folgavam muito. E conquanto com aquilo os segurou e afagou muito, tomavam logo uma esquiveza como de animais montezes, e foram-se para cima....

...Bastará (isso para vossa alteza ver) que até aqui, como quer que se lhes em alguma parte amansassem, logo de uma mão para outra se esquivavam, como pardais (com mêdo) do cevadouro. Ninguém nãolhes ousa falar de rijo para não se esquivarem mais. E tudo se passa como êles querem - para os bem amansarmos! (p.49)

...Nesse dia, enquanto ali andavam, dançaram e bailaram sempre com os nossos, ao som de um tamboril nosso, como se fôssem mais amigos nossos do que nós seus. Se lhes a gente acenava, se queriam vir às naus, aprontavam-se logo para isso, de modo tal, que se os convidáramos a todos, todos vieram. Porém não levamos esta noite às naus senão quatro ou cinco....... Os que o Capitão trazia, era um dêles um dos seus hóspedes que lhe haviam trazido a primeira vez quando aqui chegamos - o qual veio hoje aqui vestido na sua camisa, e com êle um seu irmão; e foram esta noite mui bem agasalhados tanto de comida como de cama, de colchões e lençóis, para os mais amansar.(p. 61)

Não parece ser possível, a partir deste documento fazer as ilações, ou mesmo chegar as conclusões que os autores citados chegaram. O texto é bastante claro e específico, ele revela uma profunda preocupação do narrador, inclusive dirigindo-se diretamente ao seu interlocutor "(isso para vossa alteza ver)", de evidenciar que alguma forma de contato já estaria se processando. É possível sim admitir, que algo referente à atividades de lazer, ou mesmo a História do Lazer no Brasil pudesse estar sendo observado ao nível deste documento.

Estes dois trechos da carta de Caminha, tem inúmeras referências introduzindo questões relativas ao tempo dos homens, especialmente dos homens de diferentes culturas. Inicialmente temos a descrição de uma festa, onde localizamos o trecho trabalhado pelos autores citados, interrompida pela 'esquiveza' dos nativos; posteriormente,

Movimento, Porto Alegre, v. 10, n. 3, p.133-154, setembro/dezembro de 2004 
dois parágrafos abaixo, após descrever a caminhada do capitão 'com todos nós', passando pelo rio, Caminha conclui, referindo-se duas vezes, no mesmo parágrafo, ao verbo amansar.

Observando a narração mais detalhada da Carta de Caminha, é possível afirmar a absoluta distancia do que esta sendo relatado e do que foi concluído por Penna Marinho e referendado explicitamente por Jordão Ramos, e implicitamente por muitos outros autores que os sucederam. Não seria a ausência de discussão sobre as origens do esporte no Brasil uma aquiescência ao saber já construído? Ou seria julgar que esta questão não tem a importância que esta sendo dada? É evidente o tratamento inadequado, para não dizer capcioso ao qual as fontes históricas foram submetidas. Vejamos exatamente quais são os indícios desta documentação.

No primeiro trecho, os portugueses e os índios, embora participassem das mesmas atividades relatadas, não tem uma mesma percepção do que esta ocorrendo, a participação dos portugueses na dança, não obstante a alegria dos índios, aponta para uma 'esquiveza' não compatível com o clima descrito. Esta 'esquiveza' relaciona-se ao medo (como pardais) 'do cevadouro'. A conclusão, acompanhada do sinal de exclamação, não deixa dúvidas sobre o caráter premeditado e utilitário da ação tal como foi vista pelos portugueses. A expressão 'para os bem amansarmos!' é inequívoca. A dificuldade aqui é aceitar a afirmação, feita por Caminha, segundo a qual a esquiveza dos nativos teriam como causa o medo que eles teriam do cevadouro; afinal em que se baseou o escrivão para chegar a essa conclusão? É mais viável aceitar que esta conclusão antecipa a racionalização pragmática do tratamento que os colonizadores dariam aos índios.

Esta argumentação torna-se mais explícita na citação seguinte, que se refere à noite passada pelos nativos nas naus. Amansar tornase então um conceito capaz de, senão explicar, ao menos identificar um forte componente do comportamento dos portugueses, em situações vividas nos contatos com os índios brasileiros. Notemos que estas situações relatadas por Caminha, estão permeadas por atividades objetivamente vinculadas ao prazer, para não dizer lazer, enfocados na perspectiva de sobrepor a vontade e a dimensão dos contatos posteriores. É difícil visualizar aqui, qualquer indicação que possa remotamente induzir à percepção de que estejamos diante de uma metalinguagem cujo significado pudesse ser algum tipo de prática, ou mesmo relato de prática esportiva, tal como o pretenderam os autores clássicos da área.

Movimento, Porto Alegre, v. 10, n. 3, p.133-154, setembro/dezembro de 2004 
O contato da narrativa escrita com uma cultura oral coloca ainda outras questões presentes em trabalhos bastante relevantes da historiografia recente. Ginsburg discute a relação entre a cultura letrada e escrita, em relação a cultura oral. Ainda que em outro contexto, vejamos como ele descreve a significação destas questões para Menocchio, um moleiro medieval vítima da inquisição:

Nos discursos de Menocchio vemos emergir, como que por uma fenda no terreno, um estrato cultural profundo, tão pouco comum que se torna quase incompreensível. Estecaso, diferentementedos outros examinados atéaqui, envolve não só uma reação filtrada pela página escrita, mas também um resíduo irredutível da cultura oral. Para que essa cultura diversa pudesse vir à luz, foram necessárias a Reforma e a difusão da imprensa. Graças a primeira, um simples moleiro pôde pensar em tomar a palavra e expor suas próprias opinióes sobre a Igreja e sobre o mundo.

Trata-se de um personagem europeu, vivenciando uma experiência histórica típica européia. A cultura oral que emerge, é possibilitada pela Reforma e pela imprensa, os indígenas brasileiros ao se defrontarem com a esquadra de Cabral, no relato escrito por Caminha, vivem um momento histórico de contato de linguagens, ainda que desse fenômeno nada soubessem, aspecto diferente do vivido pelo moleiro medieval:

Desse modo, viveu pessoalmente o salto histórico de peso incalculável que separa a linguagem gesticulada, murmurada, gritada, da cultura oral, da linguagem da cultura escrita, desprovida de entonação e cristalizada nas páginas dos livros.

Outra questão metodológica que deve ser apontada no trato do tema, é a sua construção temporal. Um observador externo, um colonizador, vive seu próprio tempo, diferente das populações nativas. A construção conceitual do homem do século XVI, dificilmente poderia corresponder a um outro processo civilizador instaurado e construtor de um outro tempo social.

Voltemos agora a Carta de Caminha, tendo como pano de fundo da discussão, proposta por Ginzburg, a respeito do contato entre a cultura oral e a cultura escrita. É difícil admitir a proposição assumida pelo autor, duas culturas no mesmo espaço e tempo construídos historicamente. Que dizer então deste contato entre dois tempos históricos, dois espaços geográficos e, neste caso sem dúvida, dois processos civilizadores absolutamente díspares.

7 Ginzburg, C. "O queijo e os vermes". São Paulo, Cia das Letras, 1993, p. 127.

Movimento, Porto Alegre, v. 10, n. 3, p.133-154, setembro/dezembro de 2004 
Em primeiro lugar, é preciso ter presente que as cartas narrativas de viagens constituíram um gênero "literário" muito português. Como grandes navegadores que foram em torno dos anos 1500, estas narrativas constituíram-se em documentos com alto grau de profissionalismo e competência específica, no sentido de compor os elementos que permitiriam as futuras decisões destas empresas, com grande participação estatal, voltadas para a descoberta de rotas de comércio e, posteriormente para a colonização das novas terras.

Em segundo lugar, bastaria relembrar o início do texto para compreender rapidamente a quem, e por que, Caminha redige sua carta:

\section{Senhor,}

posto que o Capitão-mor desta Vossa frota, e assim (mesmo) os outros capitães escrevam a Vossa Alteza a notícia do achamento desta Vossa terra nova, que se agora nesta navegação achou, não deixarei de também dar disso minha conta a Vossa Alteza...

Existe alguma dúvida sobre o interlocutor? Existe dúvida sobre o conjunto de documentos, entre os quais se inclui esta carta?

Não pairando dúvidas sobre estas considerações básicas, vejamos agora como discutir a utilização de um documento, produzido em um espaço geográfico igualmente determinado, para um interlocutor também igualmente determinado. Sem dúvida, tanto Inezil Penna Marinho, quanto aqueles que o secundaram, construíram um texto de ficção, para o qual a utilização de qualquer documentação teria sido absolutamente dispensável. Utilizar um documento, a par de procedimentos técnicos e metodológicos, implica em respeitar a fonte em sua integridade constitutiva; quer dizer, dar coerência as conclusões, ou indícios que estas fontes podem apresentar. Acima de tudo, é preciso sempre ter em mente que todo documento tem um interlocutor, para o qual este documento é produzido.

A transformação de um documento em fonte histórica é papel do historiador, se o historiador não efetua este cuidadoso, metódico, delicado trabalho de construir suas fontes, ocorre um ato de infidelidade ao documento, que como vimos, castiga impiedosamente seu manipulador, neste caso, o documento, em seu diálogo com o historiador, inviabiliza sua construção enquanto fonte. Temos um interessante epílogo, não existe então a possibilidade de se construir a narrativa histórica, posto que o historiador não tem existência sem dar existência às suas fontes.

Movimento, Porto Alegre, v. 10, n. 3, p.133-154, setembro/dezembro de 2004 
Constitui aspecto fundamental para a compreensão do trabalho do historiador visualizar a relação que se estabelece entre as fontes e a construção da narrativa histórica, tal premissa recupera a proposição de Lucien Febvre: "A História faz-se com documentos escritos, sem dúvida. Quando os há. Mas pode fazer-se com tudo que o engenho do historiador lhe pode permitir utilizar...". Como se vê, estamos diante de uma dupla proposição, o documento e o historiador são as peças centrais em torno das quais as fontes são construídas. Documentação e fontes são geradas a partir da intervenção do historiador, não existe uma pré-definição do que vem a ser fonte ou documento privilegiado, é o diálogo do historiador com os múltiplos indícios do passado, o motor do processo constitutivo das evidencias que sustentam o tema em estudo.

Inúmeras possibilidades de utilização de fontes e procedimentos no trato com indícios tem sido objeto de discussão e análise teórica, dentre os aspectos discutidos no processo de construção da documentação histórica, as inovações tecnológicas tem em situações diferentes, crescentemente, imposto uma enorme velocidade na incorporação de elementos novos nesta discussão, por exemplo: o computador e a internet desencadeiam questões e problemas surpreendentes para nossa atividade didática e de pesquisa, da mesma maneira a imprensa periódica desencadeou, em seu momento inovador, problemas equivalentes.

A presença do computador interpôs questões significativas não apenas no desenvolvimento das comunicações e da tecnologia, como também para o nosso cotidiano e no exercício de nossa atuação profissional. É bastante freqüente encontrar análises, comparando as transformações ocorridas com a emergência do computador àquelas provocadas pela introdução da maquinaria, provocando a Revolução Industrial, esta percepção é bastante disseminada por Bill Gates através da imprensa.

A respeito do impacto dos computadores, Jeremy Rifkin, ${ }^{9}$ coloca uma nova somatória de questões relativas a uma nova revolução na maneira de viver estas inovações tecnológicas. Tratase da transição para a sociedade pós-industrial; para ele os programas de computadores estão articulando o sistema de agendamento horário ao sistema de planificação. Só os computadores podem determinar, com exatidão, o momento

8 L. Febvre Combats pour l'histoire, Paris, 1953, p. 428

9 Jeremy Rifkin Time Wars - The Primary Conflict in Human History. New York, Touchstone Book, 1987.

Movimento, Porto Alegre, v. 10, n. 3, p.133-154, setembro/dezembro de 2004 
acurado, no futuro, em que um evento necessitando de precisão milimétrica se verifica. Só o computador pode dimensionar um tempo, que se define na conjunção de inúmeros fatores físicos, biológicos e, por que não sociais. Lançar um foguete, embora tarefa relativamente simples hoje em dia, pode dar idéia do que estamos falando, é impossível, sem a velocidade de cálculos do computador, empreender, com sucesso, o lançamento de qualquer artefato desta natureza. O fato é que o processo de decisão e o evento passam a ser mediados, não mais pelos mecanismos decisórios usualmente conhecidos por democráticos, ou mesmo autoritários, onde afinal de contas o processo de decisão se refere ao universo das pessoas. Agora, e quanto mais exata a tarefa, a mediação humana, está cedendo lugar a um instrumento que articula tempos de maneira mais eficiente, complexa e confiável, ao menos do ponto de vista dos objetivos estabelecidos e programados.

Quais as conseqüências desta reflexão para melhor compreender a relação do historiador com suas fontes na produção da documentação histórica? Imaginemos por um breve momento a possibilidade de estarmos produzindo conhecimento histórico no futuro; como então utilizaríamos este formidável instrumento de armazenamento e organização de dados chamado computador? Seria correto falar de uma História Computacional, na mesma medida em que falamos de História Oral?

Para aprofundar esta e outras inquietações advindas da velocidade e volume das inovações tecnológicas e seu impacto em campos do conhecimento didático e científico, vejamos esta mesma problemática através de um outro ângulo de observação. De maneira semelhante, Bill Gates, em entrevista televisionada, quando perguntado a respeito do século XXI, instado a se manifestar sobre o futuro e suas maiores características, apontou o desenvolvimento das ferramentas e das máquinas nos Séculos XIX e XX propiciando um enorme potencial físico ao ser humano, ou seja, as ferramentas e máquinas potencializaram a força muscular agregando potencia e ritmo aos padrões corporais, da mesma maneira agora, no Século $\mathrm{XXI}$, os computadores propiciariam o mesmo redimensionamento das capacidades intelectuais do ser humano. Como se vê, há uma clara conexão entre a proposição de Rifkins sobre os cenários futuros, substituindo os fatos nas tomadas de decisões, implicando na intermediação de instrumentos, no caso o computador para a tomada de decisões levando em conta a necessidade de lidar com cenários mutáveis, e o argumento de Gates afirmando o desenvolvimento do

Movimento, Porto Alegre, v. 10, n. 3, p.133-154, setembro/dezembro de 2004 
potencial operacional do intelecto, ao agregar novos equipamentos no processo de construção do conhecimento.

Voltemos então ao historiador do futuro e suas indecisões ao lidar com esse formidável aparato documental representado pelos bancos de dados disponibilizados pelos computadores, imaginemos as possibilidades temáticas novas, como, por exemplo, no que se refere às Histórias tais como das emoções, das decisões ou das informações, possíveis de ser estudadas a partir dos 'chats/ home pages' e fluxo de informações existentes na rede mundial, aliás, imaginemos o que é produzir documentação a partir da existência de uma rede mundial de comunicações escritas, sem falar nas imagens!

Estas questões propostas, provavelmente relativas à constituição de um novo universo emocional, e também de uma percepção de tempo que incorpora, no presente o futuro, ainda que como cenário de possibilidades, bem como a questão teórica sempre presente, contida na multiplicidade de momentos vividos pelo humano então profundamente globalizado, colocam para a discussão das fontes questões 'novas'a respeito das quais pretendemos nos referir.

Voltemos aos anos 1940 momento da também e então 'nova' invenção, o gravador de som popularizado e, em pouco tempo, miniaturizado. Este pequeno aparelho colocou, a partir dos anos 1950 a possibilidade tecnológica de construção de um novo tipo de fonte para o historiador, possibilidade que se materializaria a parir dos anos 60 especialmente com Mercedes Villanova trabalhando precursoramente na Universidade de Barcelona, nascia a História Oral, iniciava-se a discussão em torno do presentismo das fontes orais, seu grau de subjetividade e interferência do historiador. Afinal falávamos de história oral ou de depoimentos orais?

Em meados dos anos 70, eventos de envergadura internacional, bem como a constituição de grupos de pesquisa, com projetos mais elaborados, superando a percepção inicial voltada para o registro de testemunhos, especialmente de militantes políticos e operários, definem novas perspectivas para a utilização e divulgação dos registros orais tomando direções mais abrangentes.

Sem maiores detalhes sobre a evolução da chamada História Oral, ${ }^{10}$ gostaria de propor a discussão deste tema a partir de três experiências de orientação realizadas em momentos e circunstâncias diferentes, a partir daí, enfrentar a problemática relativa ao significado

10 Para uma síntese das grandes questões relativas a História Oral nos dias de hoje, ver Usos \& Abusos da História Oral, Janaína Amado e Marieta de Moraes Ferreira, coordenadoras. Rio de Janeiro: Editora da Fundação Getúlio Vargas, 1996.

Movimento, Porto Alegre, v. 10, n. 3, p.133-154, setembro/dezembro de 2004 
da narrativa oral na pesquisa em Educação. O primeiro trabalho foi apresentado como dissertação de mestrado, em 1989 por Roberto Rodrigues Paes, ${ }^{11}$ o segundo trabalho é a monografia de Magda Sarat Oliveira $^{12}$ finalizada em 1998, finalmente utilizarei uma experiência de orientação em andamento, trata-se de texto em elaboração de Francisca Maria Mendes Marques. ${ }^{13}$

Antes de prosseguir na discussão das questões propostas, relacionadas a construção da documentação histórica e oralidade, julgo ser útil justificar as razões da escolha destes trabalhos, bem como explicitar os procedimentos adotados na elaboração deste texto. Dentre as monografias e teses orientadas, busquei exemplos de profissionais que continuaram, ou que exercem atividade acadêmica relativa ao tema de estudo. Também procurei enfocar pesquisas nitidamente diferenciadas, quer pela relação do pesquisador com o tema problema, quer pela aproximação do pesquisador com os sujeitos pesquisados. No primeiro caso o pesquisador poderia ter sido sujeito de uma pesquisa semelhante, no segundo caso não existia esta possibilidade, posto que os sujeitos viveram outra época, bem como experiências individualizadas e particulares. Finalmente no último caso, ainda em andamento, o trabalho aproxima-se de um memorial, onde, neste sentido o depoimento é, simultaneamente oral e escrito. Não nos esqueçamos, neste caso que há um método de pesquisa e um método de exposição, se na exposição a forma escrita apresenta-se única, na pesquisa, o depoimento oral na construção do texto, foi fundamental, ainda que este depoimento tenha sido exclusivo ao orientador.

O trabalho de Roberto Paes é efetuado por um profissional que viveu intensamente o seu tema, tanto como atleta de nível nacional, quanto como acadêmico envolvido com a docência da

11 Aprendizado e Competição Precoce: O Caso do Basquetebol é o título da monografia apresentada no programa de Pós Graduação em Educação da Universidade Metodista de Piracicaba, na área de Filosofia da Educação. Com esse mesmo título, este trabalho foi publicado pela Editora da Universidade Estadual de Campinas em 1992. O autor é, desde 1995, professor da Faculdade de Educação Física da Universidade Estadual de Campinas tendo se doutorado em 1999 pela Faculdade de Educação da Unicamp.

12 Lembranças de Infância: Que História é essa? Dissertação de Mestrado apresentada junto a área de História e Educação do programa de Pós Graduação da Faculdade de Educação da Universidade Metodista de Piracicaba em 1999. A autora é atualmente professora da Faculdade de Educação da Universidade Estadual do Centro Oeste do Paraná, em Guarapuava.

$13 \mathrm{~A}$ autora desenvolveu uma longa carreira de educadora no ensino básico e médio, desde 1978 é professora da Faculdade de Ciências e Letras de Araras.

Movimento, Porto Alegre, v. 10, n. 3, p.133-154, setembro/dezembro de 2004 
disciplina Basquetebol; mais ainda, a questão central que motivou a pesquisa era um problema vivido pelo pesquisador, ou seja: a competição precoce não é educativa e sua eficiência, na preparação de atletas de alto nível, é bastante limitada.

Estabelecida a gênese e a motivação da pesquisa empreendida por Paes,vejamos como o depoimento oral foi proposto:

O quarto capítulo tem como subtema 'Jogo e História de Vida". Neste capítulo, procurar-se-á demonstrar empiricamente algumas experiências vividas, por praticantes de primeira linha do basquetebol brasileiro, tanto na categoria adulta quanto na categoria mini. Como roteiro teórico será utilizado o texto 'Experimentos com História de Vida', onde especificamente, será tomado como base o texto de Maria Izaura Pereira de Queiroz. ${ }^{14}$

A partir de uma experiência piloto realizada em 1986 com atletas da equipe profissional do Tênis Clube de Campinas, onde Paes era técnico, objetivando familiarizar o pesquisador com os inúmeros problemas de uma pesquisa baseada em depoimentos sobre histórias de vida, definiu-se mais precisamente o âmbito da pesquisa e sua extensão, a construção do texto privilegiou o seguinte procedimento:

A utilização desta técnica de pesquisa teve como objetivo coletar dados para um estudo relativo ao tema proposto neste trabalho. Alguns motivos influenciaram esta opção. Seguramente o fato de pertencer à coletividade observada foi um deles. Muito embora, acima de qualquer outro, a aplicação desta técnica se deu em função da possibilidade de ampliar as discussóes, privilegiando, e em certa medida, indicando a possibilidade de agregar à discussão teórica, o estudo de casos.

Uma das preocupações ao realizarmos esta pesquisa foi com relação à escolha de ex-atletas, atletas e técnicos que prestaram seu depoimento para o desenvolvimento do trabalho. Para tanto, as entrevistas foram feitas durante a Taça Brasil, versão 1986, realizada no inicio do ano de 1988, e dividida em duas partes. A primeira parte durante a fase semifinal, realizada no mês de janeiro, na cidade de Rio Claro/SP, e a Segunda na fase final, realizada no mês de fevereiro, na cidade de São Paulo/SP. Comisso acreditamos ter conseguido trabalharcom atletas e técnicos que formam a elite do Basquetebol brasileiro nos últimos dez anos. É preciso mencionar que as melhores equipes do país estiveram presentes nestes locais. ${ }^{15}$

14 Trata-se do texto Relatos Orais: Do indivizível ao divizível, apresentado em mesa redonda "Perspectivas da Pesquisa Sociológica no Meio Rural Brasileiro" durante a $38^{\circ}$ Reunião Anual da Sociedade Brasileira para o progresso da Ciência, Curitiba, PR, 1986. O volume posteriormente publicado pela Vértice em 1988 , foi organizado por Olga de Moraes Von Simson.

15 Roberto Rodrigues Paes, p.72

Movimento, Porto Alegre, v. 10, n. 3, p.133-154, setembro/dezembro de 2004 
A pesquisa objetivava, a partir de duas questões iniciais, dividir os atletas em dois grupos, tendo em vista o momento inicial em que cada um deles iniciou a prática do basquetebol (antes e depois dos 12 anos de idade). A partir desta identificação geral, a pesquisa era aberta, vejamos como, no momento da pesquisa esta questão se colocou para o pesquisador:

A não existência de um roteiro de perguntas causou-nos alguns problemas, uma vez que todo trabalho se desenvolveu de forma aberta, implicando assim algumas variáveis não controladas. Este aparente problema enriqueceu a coleta de dados, na medida em que possibilitou tratar cada caso em sua individualidade.

Esta opção de trabalho foi fundamentalmente tomada tendo em vista a vivência do pesquisador no meio. Em certa medida, poderia ser afirmada a existência de uma pesquisa participativa. Afinal, foram 20 anos de vida íntima profundamente dedicadas à prática da modalidade ${ }^{16}$

Temos aí as linhas gerais do procedimento tomado pelo pesquisador, bem como uma rápida avaliação da procedência e eficiência da técnica de pesquisa empregada, tendo em vista o tema proposto. Foi destacada a vivência prévia do autor em relação ao tema em estudo. É possível afirmar que a escolha do tema de pesquisa, no caso de Roberto Paes, deu-se muito estreitamente relacionada com a própria experiência de vida do pesquisador. Quando fizemos as primeiras discussões de orientação, dada a absoluta precariedade bibliográfica da área, e dada a extraordinária experiência de vida do pesquisador, nunca é demais lembrar que Roberto havia sido dos mais destacados atletas nas categorias menores, tendo seu estirão de crescimento dos 11 aos 13 anos. Essas constatações são importantes para entender como o tema da especialização precoce estava já incorporado na vida esportiva do autor, sabemos que no caso do basquetebol, o biotipo é muito importante no processo de aprendizagem e de definição de uma posição de jogo. É ainda relevante, para os objetivos deste trabalho, destacar que praticamente todos os entrevistados, em algum momento de suas carreiras, atuaram no basquetebol próximo ao autor.

Em síntese, os depoimentos relativos às múltiplas histórias de vida pesquisadas, constituíam, de alguma maneira, espaço vivido ou partilhado pelo entrevistador. Vejamos agora uma outra monografia, utilizando-se também de histórias de vida, onde o pesquisador não teve a menor participação prévia no tema da pesquisa, tal qual ele foi construído e vivenciado pelos entrevistados.

16 Paes, p.74

Movimento, Porto Alegre, v. 10, n. 3, p.133-154, setembro/dezembro de 2004 
Vejamos então como a pesquisadora situa seu tema em relação à proposta de utilização das Histórias de Vida:

...Algumas questões são focalizadas na pesquisa: De que forma as crianças estão presentes na história, fazendo e sendo parte dela? Como os adultos conduzem a formação das crianças no intuito de dar continuidade as gerações futuras? Os relacionamentos estabelecidos entre adultos e crianças na infância influenciam e constróem as percepções de infância posteriormente? Utilizando-se da literatura e da metodologia da história oral trabalhamos com histórias de vida, em que enfoques foram as experiências de infância de pessoas que viveram esse períodona primeira metade deste século e, hoje, tem entre 90 e 50 anos de idade.

Colocada esta premissa inicial para o desenvolvimento de nossa argumentação, vejamos como a autora, no segundo capítulo de sua dissertação: Uma forma de contar a História-identifica suas referências e opções na utilização dos relatos orais.

A proposta de Oliveira difere-se já de início da proposta de Paes, como vimos, no caso de Paes, sua própria história de vida foi inspiração e leito condutor de uma sensibilidade pessoal na coleta, identificação e análise das entrevistas e falas. No caso de, Oliveira, sua temática foi desenvolvida a partir de uma experiência profissional vivida com crianças, experiência importante para compreensão do tema, mas pouco relevante na relação com os sujeitos da pesquisa, pessoas que viveram sua própria infância em sua própria época. Esta diferença de perspectiva é muito importante ser lembrada, de um lado temos um pesquisador que, de alguma maneira centra as entrevistas em um tema vivido e motivador de seu estudo, em alguma dimensão o tema foi um problema na sua trajetória de atleta profissional, de outro lado, temos uma pesquisadora que, definindo seu tema, vai em busca das fontes para confrontar uma problemática que se constrói no interior do tratamento bibliográfico existente. Mais ainda, no caso de Oliveira, o orientador já vivera as experiências iniciais no trabalho da Pós Graduação, tendo então uma experiência acumulada maior, experiência que não garante, como pretendemos afirmar, que um trabalho orientado alguns anos depois deva, necessariamente, ter uma 'qualidade' maior.

O fato é que, na construção de seu trabalho, Oliveira teve a sua disposição um volume fantástico de textos, a grande maioria deles já em língua portuguesa, relativos a metodologia e técnicas em História Oral, textos estes não disponíveis nos anos 1980, além de um enorme acervo de trabalhos acadêmicos desenvolvidos utilizando-se desta mesma técnica, tal acertiva pode ser verificada

17 Esta síntese foi extraída do resumo da monografia de Magda Sarat Oliveira.

Movimento, Porto Alegre, v. 10, n. 3, p.133-154, setembro/dezembro de 2004 
através da variedade de fontes bibliográficas utilizadas. ${ }^{18}$ A partir da consideração desta bibliografia de apoio, a autora ouviu cinco personagens contando a história de sua infância, da de filhos, netos e bisnetos, isto equivale a dizer que a utilização das histórias de vida deu ênfase à temática infância:

As pessoas convidadas a falar foram escolhidas primeiro pelo interesse em ouvir experiências de adultos falando de sua própria infância, considerada como período que cobre os primeiros doze anos de vida; logo, todos já teriam passado por ela. Entretanto, as pessoas têm idades diferentes e optamos por trabalhar com cinco personagens nascidos em cinco décadas diferentes, cobrindo assim a primeira metadedeste século.

Começou então a busca por pessoas que tivessem idades entre noventa, oitenta, setenta, sessenta e cinqüenta anos. A princípio, o critério foi de idade, dentro da primeira metade do século, marcada também pela diversidade. Assim, foram homens e mulheres vivendo a infância com a família em diferentes lugares, com grau de escolaridade, situação sócio-econômica, cultural e religiosa diferenciada porque não queríamos definir por esses critérios e o trabalho não pretendia caracterizar uma criança especificamente... ${ }^{19}$

18 Pela ordem em que aparecem no texto, foram utilizados os seguintes autores na formulação de suas referências para compreensão das diferentes posições de abordagem com depoi9mentos orais: Maurice Halbwacks. A memória coletiva. São Paulo, Vértice - Editora dos Tribunais, 1990. Mary del Priore. História do Cotidiano e da Vida Privada, In Ciro Flamarion Cardoso e Ronaldo Vainfas Cotidiano e da Vida Privada, In Ciro Flamarion Cardoso e Ronaldo Vainfas (organizadores) Domínios da História. Ensaios de teoria e metodologia, Rio de
Janeiro, Campus, 1997. Paul Thompson. A Voz do passado: história oral, Rio de Janeiro, Campus, 1997. Paul Thompson. A Voz do passado: história oral, Rio de Janeiro, Paz e Terra, 1992. Verena Alberti Ensaio Bibliográfico. Obras Coletivas de
história oral In Tempo, Rio de Janeiro vol. 2, n. 3, pp. 206 - 219. Ecléa Bosi Memória e Sociedade: lembranças de velhos,São Paulo, Companhia das Letras, 1994. Solang Jobim Souza e Rita Maria Ribes Pereira Infância conhecimento e contemporaneidade In Sonia Kramer e Maria Isabel Leite (organizadoras) Infância e Produção Cultural, Campoinas, SP, Papirus, 1988. Janaína Amado e Marieta de Morais Ferreira (organizadoras) Usos e Abusos da História Oral Rio de Janeiro, Fundação Getúlio Vargas, 1996. Zeila de Brito Fabri Demartini Algumas reflexões sobre a pesquis Vargas, 1996. Zeila de Brito Fabri Demartini Algumas reflexóes sobre a pesquis histórico-sociologica tendo como objeto a educação da população brasileira In Demerval Saviani, José Claudinei Lombardi e José Luís Sanfelice (organizadores) História e História da Educação Campinas, SP, Autores Associados: HISTEDBR, 1998. Rosana Glat Somos iguais a vocês. Depoimentos de mulheres com deficiência mental. Rio de Janeiro, Agir, 1989. Olga Rodrigues de Moraes Von Simson e Zeila de Brito Fabri Demartini Vida Familiar de diferentes grupos étnicos em São Paulo e Campinas: educação, lazer e consumo cultural em cidades em rápida transformação (1890-1950) In Famílias em São Paulo: vivências na diferença. São Paulo, CERU/ Humanitas (Coleção Textos. Série2, n. 7), 1997. José Carlos Sebe Bom Meihy Manual de História Oral, São Paulo, Contexto, pp. 98-111, 1998. Alexandro Portelli On the peculiarities of oral history In History Workshop Journal Oxford, England, 12, pp. 96-107, 1981. Maria Cristina S. de Souza A atuação de agentes femininos no pp. 96-107, 1981. Maria Cristina S. de Souza $A$ atuação de agentes femininos no campo das relaçoes familiares em diferentes classes sociais (1850-1950) In Familias em São Paulo: vivências na diferença, São Paulo, CERU/Humanitas, Coleção Textos, 19 Magda Sarat Oliveira, p. 75.

Movimento, Porto Alegre, v. 10, n. 3, p.133-154, setembro/dezembro de 2004 
A partir destes critérios iniciais, a autora, sem recusar seu envolvimento com os personagens, os identifica enquanto sujeitos da pesquisa por características exteriores a um determinado tipo de atividade ou envolvimento, como no caso anterior, onde os sujeitos eram necessariamente atletas e técnicos de nível nacional. A existência de algum vínculo entre a pesquisadora e os sujeitos é ocasional e aleatória. Identificadas as personagens/sujeitos, para dar voz aos mesmos, já que os nomes por autorização expressa dos entrevistados foram mantidos, efetuou-se uma entrevista piloto, a título de amostragem e exercício inicial para aferição dos procedimentos. Posteriormente, após exposição individualizada dos objetivos, interesses e expectativas da pesquisadora, partiu-se para o agendamento de encontros para efetuar as entrevistas:

Não estabelecemos um roteiro de questionamentos de forma rígida, mas a conversa girou em torno de uma questão básica: Gostaria que o senhor ou a senhora me contasse um pouco da sua história de vida, especialmente no período da infância. Quais as lembranças que o senhor ou a senhora tem desse momento quando era criança, mais ou menos até os doze anos de sua vida? Começavam falando da vida e as vezes faziam longos percursos, saindo um pouco daquilo em que estávamosinteressados.

Nessemomento, procurando trazer a conversa para ocentro dos interesses, lembrava de alguns aspectos que ajudavam a organizar o pensamento, as lembranças. Por exemplo: conte-me sobre as brincadeiras ejogos de suainfância, seu relacionamento com os pais e adultos, as visitas na casa, as atividades de que os adultos e crianças participavam juntos, as lembranças da escola, da professora, dos assuntos que eram tabus, proibidos para as crianças. Nesse momento, os temas levavam a uma certa limitação dos assuntos e as lembranças tornavam-se mais claras. ${ }^{20}$

Do ponto de vista da autora, algumas constatações são importantes: as lembranças de infância situavam-se mais entre o período vivido dos sete aos doze anos, apenas um entrevistado relatou fatos relativos aos seus cinco anos; também a dificuldade de transcrever emoções presente na voz dos entrevistados, nos pequenos gestos, sorrisos, enfim ela situa aqui uma dificuldade da história de vida, a dificuldade de captar na transcrição, o contexto do depoimento. De qualquer maneira, nas transcrições ela optou pela textualização, buscando dar clareza ao leitor, sem mudanças de edição que rompessem a integridade do texto.

A percepção de que as memórias tornam-se mais explícitas a partir dos cinco/sete anos é, provavelmente um aspecto da relação da criança com o mundo, as experiências vividas até os cinco anos são muito restritas, quer pelas limitações físicas e biológicas, quer

20 Idem pp. 78-79.

Movimento, Porto Alegre, v. 10, n. 3, p.133-154, setembro/dezembro de 2004 
pelo processo de amadurecimento dos equipamentos neuromotores, ou ainda pela limitada possibilidade de vivenciar experiências emocionais e sociais.

Sobre a possibilidade de transcrever as emoções que afloram durante os depoimentos, algumas questões podem ser colocadas. A divergência entre o discurso escrito e a palavra verbalizada, do ponto de vista da documentação histórico, esta no estagio atual do desenvolvimento tecnológico, mal situada. Enquanto não tivermos, arquivos de depoimentos e eventos gravados em filmes ou tapes, a emoção que esta sendo colocada se refere ao momento da construção da narrativa, ao momento da entrevista ou do depoimento, não ao momento do tema que esta sendo estudado. É particularmente difícil, para não dizer quase impossível, aferir com algum grau de precisão a natureza e a causalidade da emoção que esta aflorando; como então pré definir que esta emoção, importante para o depoimento e para o conhecimento da pessoa no momento da entrevista, ou ainda para a compreensão de sua vida emocional, é também importante para o tema em estudo, no caso a infância?

Por outro lado, Norbert Elias ${ }^{21}$ chama a atenção para a possibilidade de que o estudo da emoção humana, possa ser um importante e decisivo vestígio para conhecer a natureza humana, mais ainda chama a atenção para a ambiguidade e mal uso do conceito de emoção, freqüentemente se referindo aos sentimentos, neste sentido seria de todo conveniente atentar para esta questão substantiva. Ao escrever e nominar a emoção do momento, transparente e contagiante, estaríamos verdadeiramente nos referindo à sentimentos que afloram. De qualquer maneira é uma questão relevante para a percepção do que esta ocorrendo na construção da documentação oral.

Finalmente, um aspecto importante do trabalho de Oliveira esta presente em suas conclusões. Enquanto no trabalho de Paes, o material produzido pelas entrevistas confirmou as hipóteses iniciais do autor, no trabalho de Oliveira "algumas dúvidas foram diluindo-se e outras foram surgindo ao longo da caminhada" (191). Para nós que vivenciamos o processo de construção de ambos os trabalhos, essa diferença verificada no processo de pesquisa, revela uma faceta da relação do pesquisador com sua própria história de vida, seu objeto de pesquisa e a forma pela qual a pesquisa foi conduzida.

21 Ver a esse respeito "On human beings and their emotions: A process sociology essay" In The Body, Michael Featherstone (organizadores)

Movimento, Porto Alegre, v. 10, n. 3, p.133-154, setembro/dezembro de 2004 
É relevante, antes de nos debruçarmos sobre a terceira experiência de orientação ainda em andamento, retomar uma questão posta a partir destas duas experiências no trato com o documento oral, ou seja: o que é e como se constitui a evidência oral?

Esta questão pode ser pensada em inúmeras direções: tudo aquilo que uma pessoa viva ou em vida contou a alguém ou a um instrumento eletrônico, gravador ou video tape por exemplo. Também não se pode esquecer da tradição oral, mais precisamente das formas pelas quais as gerações transmitem às suas sucessoras sua cultura. Por que não mencionar as lembranças e as reminiscências pessoais e familiares, ${ }^{22}$ cabe também aqui uma primeira chamada de atenção para a proximidade entre as reminiscências e os memoriais.

Da mesma maneira gostaria de enfatizar que o processo de produção da documentação oficial, aquela documentação tão enfatizada por Ranke, ${ }^{23}$ com forma fixa, precisão cronológica e multiplicidade de evidências, como a "prima dona" da documentação confiável, sofreu um duro revés e forte contestação quando do episódio de Watergate, basta ainda lembrar, para não irmos tão longe, como eram produzidos os documentos de confissão dos presos políticos brasileiros nos anos 1960 - 1970. Para não falar da Inquisição. Afinal é preciso estender nossa tolerância para compreender o documento e sua relação com o historiador. Eis aí a questão central, o historiador é o produtor da documentação histórica. É preciso buscar, não apenas no mundo circundante, mas também no interior do historiador, nas suas emoções, na sua experiência, na sua intuição, para não dizer faro, as múltiplas configurações que possibilitam a ele se relacionar com indícios e, a partir daí, construir evidências, documentando seu próprio raciocínio. O depoimento oral coloca esta questão mais próxima, não se trata da bipolaridade entre objetividade e subjetividade, uma não existe sem a outra e as duas são faces de uma mesma moeda: a relação entre o historiador e as fontes.

22 Ver a respeito o trabalho de Jan Vansina Oral Tradition as History, Madison, Wisconsin, 1985, trata-se da discussão sobre a História em sociedades não alfabetizadas.

23 Leopold Von Ranke The Theory and Proctice of History, Indianápolis\& New York, Books - Merrill Co.,1973. Creio que Ranke sintetiza o pensamento mais sistemático e tradicional na Historiografia no que se refere a maneira de conceber e validar hierarquicamente a utilização das fontes.

Movimento, Porto Alegre, v. 10, n. 3, p.133-154, setembro/dezembro de 2004 


\section{Historical sources and orality}

Abstract: the present text systematizes the relations between the historian and his sources, seeking to elucidate theoretical and methodological issues emerging from the historical narrative. Two conceptual issues sustain the text. One refers to the building of narratives from a traditional written source, indicating the limitations of the possibilities of knowledge of cultures that don't use written language. A second issue emerges from the multiplicity of times of the historian, from his interaction with the sources, the linearity of the written narrative also limits the possibilities of knowledge of dominated groups. The text finalizes pointing a central issue on the debate of oral history, that is, the historian as a producer of historical documentation. Keywords: Oral History, Historical Sources, Historical Documentation.

\section{Fuentes históricas y oralidad}

Resumen: el presente texto sistematiza las relaciones entre el historiador y sus fuentes, procurando elucidar cuestiones teóricas y metodológicas emergentes de la narrativa historica. Dos cuestiones conceptuales vertebran el texto. Una se refiere a la construcción de narrativas a partir de una fuente escrita tradicional, indicando las limitaciones de las posibilidades de conocimiento de culturas que no utilizan la lenguaje escrita. Una segunda cuestión emerge de la multiplicidad de tiempos del historiador, a partir de su interacción con las fuentes, la linearidad de la narrativa escrita también limita las posibilidades de conocimiento de grupos dominados. El texto finaliza apuntando para una cuestión central en el debate de historia oral, esto es, el historiador como productor de documentación histórica. Palabras-clave: Historia Oral, Fuentes Historicas, Documentación historica. 
Morimento, Porto Alegre, v. 10, n. 3, p.133-154, setembro/dezembro de 2004 